\title{
Mise-en-Scène Analysis on Heteronormativity in Queer Narrative "San Junipero" from Black Mirror
}

\author{
$1^{\text {st }}$ Dominick Wulandhani \\ English Studies Program, Faculty of \\ Humanities, Universitas Indonesia, \\ Depok, Indonesia \\ dominick.wulandhani@ui.ac.id
}

\author{
$2^{\text {nd }}$ Andika Wijaya* \\ Linguistics Department, Faculty of \\ Humanities, Universitas Indonesia, \\ Depok, Indonesia \\ anwi49@gmail.com
}

\begin{abstract}
As one of the most interesting episodes from the famous sci-fi British TV series Black Mirror, "San Junipero" warrants analysis, specifically from the perspective of science and technology. Nevertheless, gender and LGBT issues have not commonly been explored in sci-fi content like Black Mirror. Through an analysis on the mise-en-scène, or cinematographic elements (setting, color, costume, camera work, and performance), and the representation of queer characters in the media, this article attempts to identify whether the episode, as a queer narrative - dubbed "a celebration of queerness" by the fans-is really free from any heteronormativity elements. The study found that heteronormativity is still depicted in the episode because stereotypes of queer characters are still used to some degree in portraying the lesbian characters. As a heterotopia, according to Foucault [1], the establishment of the queer characters in "San Junipero" also fits Rich's [2] theory on compulsory heteronormativity. Nevertheless, not all aspects of the episode suggest pure heteronormativity. It must be admitted that there are some efforts to create an empowering queer narrative through the establishment of a non-stereotypical identity in the female-female relationship.
\end{abstract}

Keywords-Mise-en-scène, Heteronormativity, Textual Analysis, Queer Studies, TV Series

\section{INTRODUCTION}

Having received Emmy Awards in 2017 in the categories of Outstanding TV Movie and Outstanding Writing, the British science-fiction TV series Black Mirror's episode "San Junipero" has successfully become one of the show's most popular episodes among the fans. Major reviewers regarded this episode as being filled with hope and optimism and as having a heartwarming ending that brings joy [3]. Although described as having some unhappy elements in it [4], "San Junipero" is more likely to be acknowledged as "bittersweet" [5]. Furthermore, the episode's amazing style and soundtrack evokes a nostalgic feeling of the '80s [6], which makes the episode itself considered a period piece, aside from being called a "modern fairytale" [7].

San Junipero is a made-up system that stores people's memories and projects them in a virtual town database. This system serves the idea of living eternally because people can at least have a taste of immortality by having their memories uploaded to the system. The episode's main story is about a bittersweet romantic relationship between Yorkie, a 61-yearold gay woman who has been paralyzed for 40 years after a tragic car crash, and Kelly, a woman of the same age who is terribly ill after having been left to die by her daughter and husband.

These sick or dying elders are given the chance to visit San Junipero every week for five hours beginning in the evening until midnight. All they have to do is put a round, small, white device on their temple, close their eyes, and sleep. The device allows their consciousness to be transferred to the virtual town's database. Each person can choose their own time setting for the town each time they visit it, and this decision contributes to their appearance and age. For example, Yorkie is a 61-year-old woman, but when she visits San Junipero, she chooses the ' 80 s era, so she appears as her 20-year-old self in that town.

When visiting San Junipero in the 1980s setting, Yorkie accidentally meets a girl named Kelly, a free-spirited and adventurous party girl with whom she instantly falls in love. However, since the beginning, Kelly has never really sought a serious relationship due to her traumatic past in her marriage. She also admits that she only visits San Junipero to have fun before she dies. When she later dies, Kelly does not want her memories to be uploaded to the system, unlike Yorkie, who wants the eternal life San Junipero offers. Even so, through her short, yet dynamic interaction and relationship with Yorkie, Kelly finally agrees to be uploaded to the system. She then lives eternally together with Yorkie in San Junipero.

The fact that both Yorkie and Kelly end up happily ever after together in San Junipero is something that captivates the viewers, especially those from the queer community because this episode highlights the happiness that queer people get from finding their escape (Brammer, 2017). This is different because most queer films focus on tragedy, bringing out themes like death and illness, like in 1985 (2018), which shows how AIDS is like a death sentence; a temporary happiness, like in A Nice Quite Life (2018); and even violence, like in Happy Prince (2018), which shows the struggle of being imprisoned for being gay. Although it is true that there are several queer narratives that arise from struggle, such as Philadelphia (1993) and Moonlight (2016), having a queer narrative in which the couple joyfully rides off in a convertible toward the sunset is not something easy to find (Brammer, 2017). Nevertheless, in general, Black Mirror always provides a twist with a glimpse of darkness in each episode that makes most of them considered as tragic. Just like in any other episode of Black Mirror, Charlie Brooker, the director of the episode and creator of TV series, seems to leave a small grey area that raises the question of whether San Junipero is a perfect example of an empowering queer narrative or not.

This article aims to reveal and criticize how heteronormativity works and is reflected in San Junipero, which already considered a progressive queer narrative, through a critical analysis of the cinematographic elements and characters, including their background in relation to issues about heteronormativity, queer existence, and queer portrayal in the media. 


\section{METHOD}

In this qualitative research, "San Junipero," the third episode of season four from the TV series Black Mirror, will be analyzed as the main data. In providing a deep, critical text analysis regarding heteronormativity and queer existence, this paper will examine several cinematographic elements in the episode, including the setting of time and location, color, costume, camera work - specifically the lighting and shot size - and performance or acting. This paper will only examine certain selected scenes that are relevant to the issue of queer representation and queer existence in media as well as the issue of heteronormativity in queer narratives.

\section{RESULT AND DISCUSSION}

\section{A. Analysis of the mise-en-scène of "San Junipero" Location and Setting}

The episode itself generally takes place in two different places: real life and the San Junipero database. Drage [8] describes San Junipero as a "VR Californian beachside town." Located on the beach, San Junipero is basically a small town with several bars and living areas. In the episode, Kelly addresses San Junipero as a "party town" because most activities in the town take place at Tucker's, a bar where Yorkie first meets Kelly. Tucker's is almost always the first place to visit whenever characters come to San Junipero, hinting that Tucker's is the heart of the town and the favorite go-to place. While in real life, the setting is an opposite kind of place. Everything occurs either in a nursing home or hospital.

In general, setting affects the mood in a film. These two places in general create a contradictory mood. In San Junipero, the mood is very light and fun. The place itself is very dynamic and filled with many people who are actively moving and going to do various kinds of activities. While in real life, the mood is very subtle and calm. Every movement in the real world place is not as dynamic as in San Junipero. The place has some crowds, yet they do less activities than those in San Junipero.

\section{Color}

Even though San Junipero is located in a coastal area and gives a kind of summer vibe, the color tone used in the episode is rather cold. Most of the scenes take place in the evening and at night, which makes the color blue and its dark shades dominant. According to Selby and Cowdery [9], cold colors, such as blue and green, suggest pessimism and calmness. To be specific, chromodynamics, which is the study of the physiological effects caused by observing color, suggests that blacker or darker hues evoke negative emotions, such as sadness, and symbolize decay [10].

Neon colors are also dominant in San Junipero, specifically pink and blue neon colors, which also establish a shade of purple. According to Page (1998), the designer of the bisexual pride flag, the blue and pink colors are meant to overlap, creating a shade of purple. He also suggests that the color pink represents same-gender attraction (homosexuality), and blue represents opposite-gender attraction (heterosexuality), while purple represents the combination of attraction to the same gender and the opposite gender.
In real life, however, these bisexual neon colors are not seen anywhere. The color tone is not as cold as the one in San Junipero, yet it is not considered warm either. Neutral colors, such as white and gray, seem to be dominant when the setting takes place in the hospital. This white hue, according to chromodynamics, evokes a rather positive emotion because it highlights cleanliness, innocence, and purity [10]. The fact that these colors exist in the hospital, where Yorkie stays in a coma for 40 years and where her life ends, highlights her disability and shows how the place becomes her resting place.

Meanwhile, in Kelly's nursing home, warm colors, mostly orange, appear with a tendency toward a darker hue. Warm shades evoke warmth and excitement [11], while, as mentioned before, darker hues symbolize sadness and decay. These colors then symbolize Kelly's disability and foreshadow her death that takes place in the nursing home while also highlighting the heartwarming eternal life that has been waiting for her in San Junipero.

\section{Costume}

Both Yorkie's and Kelly's costumes show a specific different clothing style. Appearing as a shy, bespectacled gay woman, Yorkie's clothing style is more casual. She mostly wears T-shirts, basic covers, like a long-sleeve shirts or denim jackets, and shorts. The color tone for Yorkie's clothing is more subtle and softer. She mostly wears clothes with pastel pink or blue as the colors. This simple clothing style with its calm tone colors seems to fit Yorkie's reserved personality.

Meanwhile, Kelly is the opposite. Her clothing style is always exaggerated with various kinds of accessories, such as large earrings and multiple necklaces, or stand-out covers that are shining and glittery. She also uses bolder colors for her clothes, such as deep green and purple, which makes her clothing style extraordinary. This exaggerated clothing style with its bold colors clothes seems to fit Kelly's vivacious energy and outgoing personality.

\section{Camera Work}

The cinematographic aspects in San Junipero play a great role in supporting the establishment of the narrative, especially through the shot sizes and the lighting. The shot sizes mostly used in the episode are the long shot, medium shot, close-up shot, and large close-up shot. According to Selby and Cowdery [9], close-up and large close-up shots in general highlight emotions, intimacy, vital moments, and personal relations to the subject. There are a few long-shot and medium-shot scenes in the episode, but there are not as many as the close-up and large close-up shot scenes.

On the other hand, in terms of lighting, this episode shows a consistent use of low lighting, which, according to Selby and Cowdery [9], supports a gloomy vibe and highlights sadness. Based on these two aspects, emotions and feelings are the subjects that seem to be highlighted the most in this episode.

\section{B. Digging Deeper: An Analysis of Heteronormativity Depicted in San Junipero}

\section{San Junipero: A Heaven for Queers?}

The concept of heterotopia is explained by Foucault to "have the curious property of being in relation with all the other sites, but in such a way as to suspect, neutralize, or invert the set of relations that they happen to designate, mirror, or 
reflect" [1], which means that heterotopic spaces can mirror everyday values in real life yet also have the possibility of not adopting certain values, as there is no certain norm that heterotopias follow, even though these sites are constituted by all culture [12]. Deriving from that concept of thinking, it means that it is possible that all values and ideologies in the current society we live in right now, including patriarchy and heteronormativity, are seen and depicted in San Junipero.

If we attempt to connect this with the bisexual signifier discussed earlier, in a deeper analysis, this signifier then appears as something far from the word "empowering." In this narrative, night life and all related activities, such as drinking at the bar, having fun dancing all night long, and hooking up with strangers, are highly connected with both queer characters. This gives the impression that queer people are closely related to only trivial activities. Not only that, the fact that the bisexual signifier colors become the base decoration for the bars somehow strengthens the connection between queers and the nightlife activities at the bar, making them look like hedonists. Furthermore, this particular case has the possibility of being sensitive and problematic because it might lead to giving a false depiction about queers.

Between Success and Stereotypical: An Analysis of the Queer Characters

According to Dhaenes [13], many scholars argue that the representation of queers in media is still rather heteronormative in the way that it still fits a binary and follows rigid perspectives about biological sex, gender, and sexuality [14]. According to Seif [14], most media, specifically television, still dominantly present heteronormative depictions of homosexual characters, namely queers being portrayed as selfless, very sexual, or even fitting a very rigid gender stereotype in relation to masculine and feminine qualities. This section will specifically discuss these heteronormative aspects as they are depicted in San Junipero (2016) through the representation of the queer characters Kelly and Yorkie.

\section{Gendered stereotypes and sexuality binary}

Both Kelly and Yorkie are the opposite of each other in terms of personal traits and even clothing style, and these differences seem to put them in binary opposition to each other. Their personal characteristics, in relation to their sexuality, seem to put both of them in certain dichotomies. According to Laporte [15], female homosexual relationships work similar to heterosexual relationships, in which there is a stereotypical label and role for each person in the relationship. In general, there are two stereotypical types of lesbian: the "butch," or masculine role and characteristics, and the "femme," or feminine role and characteristics [16].

Gomez [17] also argues that this label also works in terms of racial dynamics in Western society, where the femme is usually thought to be white-skin, whereas the butch is usually thought to be black-skin. Levitt and Hiestand [18] add that butches are usually expected to be "the leaders" as well as emotionally tough and sexually dominant.

Based on previous explanations, Yorkie and Kelly's characteristics seem to fall under these stereotypical labels. Kelly's characteristics seem to generally fit the butch stereotypes, as she is a black woman who is sexually more dominant and experienced in terms of relationships. Her clothing style, which consists of bold-color clothes and accessories, support the establishment of her aggressive personal traits. Meanwhile, Yorkie's characteristics seem to generally fit the femme stereotypes, as she is a white woman who is sexually more passive and rather reserved, not to mention the fact that she falls for Kelly in the first place and her soft-color based clothes, which support the establishment of her timid personality.

Nevertheless, there are indeed several attempts to lessen the stereotypical female homosexual characterizations of Kelly and Yorkie. Even though Kelly is sexually dominant, she does not show any significant masculine mannerisms, behaviors, and style. She is not depicted as emotionally tough either. While Yorkie, even though she is way more reserved and sexually passive, is not necessarily feminine in terms of her personal traits and clothing style as she does not wear makeup or dresses. Moreover, Yorkie has been a homosexual since the beginning, not a straight girl who is suddenly crazy in love with a sexually dominant non-heterosexual girl, which opposes Gomez's [17] argument about the femme who is a straight girl falling in love with a butch.

\section{Victimization}

According to Dhaenes [13] and his research regarding the representation in the queer teen narrative Glee, gay characters are mostly portrayed as victims. He describes how the gay teen characters in the series are portrayed as being helpless, having sad lives, and nearly dying because of certain illnesses or suicide [13]. In San Junipero (2016), Kelly and Yorkie are portrayed as weak elders who are technically dying: Kelly is suffering from a certain illness, while Yorkie has been in a coma and has been paralyzed for 40 years.

Not only experiencing physical struggles, both characters have also been victimized emotionally. Kelly admits that she has had a tough life ever since her husband decided to leave her to die, while Yorkie shows that she has been hurt by her family rejection through the act of escaping her house. To sum up, both queer characters in this episode are victimized both physically and emotionally.

Love through Melancholy: Lesbian Existence in San Junipero

Both characters grow a personal bond between each other through sadness. This exactly fits Rich's [2] concept of lesbian existence in that it is built through melancholy. The relationship between the two females exists as a refuge from abusive male behavior and heteronormativity in general. Although it may sound empowering because it signals that both of these damaged women seek power in each other by staying together, it might actually not be like this because the existence of the romance between them is based on pain caused by heteronormative society. This fact makes the episode appears as another tragic love story, just like most queer narratives, according to Brammer (2017).

Another thing that makes the lesbian existence in this narrative rather questionable is the ending. Even though Kelly decides to move to San Junipero to live happily ever after with Yorkie, her motive is still unclear and rather questionable as to whether is it because she wants to live together with Yorkie or only because she does not want to be alone. This assumption grows when Kelly decides to marry Yorkie, and she admits that it is only an act of kindness so that Yorkie can 
move to San Junipero and "pass over," as she says: "[I married you] to help you pass over, as a...kindness..." because to move permanently to San Junipero, someone who has a personal relationship with Yorkie, be it a family member or spouse, must sign a letter of permission. Kelly does not mention anything about her being in love with Yorkie, and her sole motivation is only to help.

At the end, Kelly's statement about being ready for the rest of it becomes questionable as it does not really show her true intention about moving to San Junipero, whether is it purely because of Yorkie or because she does not want to continue suffering from her illness. This decision is not supported by any explicit statement from Kelly about whether she is moving to San Junipero because of Yorkie, as she states, "all things considered, I guess I'm ready."

The fact that at the end, Kelly's body is buried in the same graveyard as her husband and her daughter somehow highlights the question even bolder because there might be an indication that Kelly is still linked to her constitutional heterosexual family. The fact that the lesbian relationship and its intimacy only occurs in the heterotopic space, not in real life, shows that lesbianism or homosexuality exists as secondary to the heteronormative relationship.

\section{CONCLUSION}

Through a detailed analysis of several mise-en-scène elements, San Junipero, which is claimed to be a perfect sample of an empowering queer narrative, apparently still contains some issues regarding stereotypes of queer characters and homosexual relationship existence. The queer existence in this narrative fits Adrianne Rich's [2] critique, and the depiction of queers in this episode still fits certain stereotypical labels that exist in lesbian relationships as their characteristics seem to fall into dichotomies, making both characters exist as a binary opposition to each other. Even so, some attempts have been made to make this narrative empowering, especially in terms of the color, which apparently uses the color symbol of bisexuals. Although the bittersweet ending can also be considered an improvement in the history of queer narrative in the media, it still arguably needs much work.

For further research, I am suggesting a discussion of the episode from another angle, for instance, from the perspective of psychology regarding how this episode shows an act of escapism by queers or how San Junipero, as a space and place, works as an escape mechanism for queers. Another interesting angle would be from the perspective of an able-bodied study in relation to a queer study because life in the real world and that in the San Junipero system show a contrast in having an able-body and a disable body. Another mise-en-scène analysis would also work, especially if the discussion can focus more on elements that have not been discussed, like music and more varieties of camera technique, such as the use of focus or the camera composition technique. An additional analysis on queer stereotypes in terms of marriage and queer sexuality would also be a valuable contribution to this field.

\section{ACKNOWLEDGMENT}

Much appreciation for Andika Wijaya who had always been supporting the whole process of producing this article, including providing very useful sources, theories, critical reviews, and even the fund. This work was also supported by
Universitas Indonesia's Research Grant (PITMA B 2019) managed by DRPM UI/Indonesian Ministry of Research, Technology, and Higher Education's Research Grant (PDUPT 2019) managed by DRPM UI.

\section{Closing}

Utmost gratitude and respect for $\mathrm{Hj}$. Masriyah Amva and her students in Pondok Pesantren Kebon Jambu Al Islamy, Cirebon, and FIB UI community service program for introducing us into this exceptional pesantren.

\section{REFERENCES}

[1] Foucault, M. (1986). Of other spaces: utopias and heterotopias (J. Miskowiec, Trans.). Baltimore, MD: The Johns Hopkins University Press. Retrieved on January 4, 2019 from http://web.mit.edu/allanmc/www/foucault1.pdf

[2] Rich, A. C. (1980). Compulsory heterosexuality and lesbian existence. Signs: Journal of Women in Culture and Society 5(4), 631-660. Chicago, IL: The University of Chicago Press.

[3] Holland, L., Nicholson, R., Bakare, L., Lee, B., MacInnes, P., Aroesti, R., Mumford, G. (2016). Battle of the bastards to San Junipero: what was the best TV episode of 2016. The Guardian. November 18, 2018 https://www.theguardian.com/tv-and-

radio/tvandradioblog/2016/dec/21/best-tv-episode-2016-game-ofthrones-black-mirror-westworld

[4] David, A. (2016). How to watch all 'Black Mirror' episodes, from worst to best. CNN Philippines. November 18, 2018 http://cnnphilippines.com/life/entertainment/television/2016/10/24/bla ck-mirror-ranked-episodes.html

[5] Poniewozik. J, Hale. M, Genzlinger. N, \& Lyons. M. (2016). The memorable TV episodes of 2016. New York Times. November 18, 2018 https://www.nytimes.com/2016/12/28/arts/television/the-memorabletv-episodes-of-2016.html

[6] Jeffery, M. (2017). Ranking all 19 episodes of Charlie Brooker's chilling Black Mirror. Digital Spy. November 18, 2018 http://www.digitalspy.com/tv/black-mirror/feature/a780434/blackmirror-episodes-ranked-charlie-brooker/

[7] Dibdin, E. (2016). The 20 TV episodes from 2016 you absolutely cannot miss. Esquire. November 18, 2018 https://www.esquire.com/entertainment/tv/a51786/best-tv-episodesof-2016/

[8] Drage, E. (2018). A virtual ever-after: utopia, race, and gender in black mirror's "San Junipero". In A. M. Cirucci, \& B. Vacker (Eds.). Black Mirror and Critical Media Theory, 27-40. Maryland: Lexington Book.

[9] Selby K. \& Cowdery R. (1995). Looking at aspects of a media text in: how to study television. How to Study Literature. Palgrave, London. DOI: https://doi.org/10.1007/978-1-349-12829-7 3

[10] Richmond, V. \& McCroskey, J. (2000). Nonverbal communication in interpersonal relations. Boston, MA: Allyn and Bacon.

[11] Lee, K. S. (2015). The color of the year: a textual analysis of pantone's color communication techniques through the application of Barthes' semiotic. June 6, 2019 https://core.ac.uk/download/pdf/58826728.pdf

[12] Sudrajat, I. (2012). Foucault, the other spaces, and human behavior. Social and Behavioral Sciences. $28-34$. DOI: 10.1016/j.sbspro.2012.03.004

[13] Dhaenes, F. (2013). Teenage queerness: negotiating heteronormatvity in the representation of gay teenangers in Glee. Journal of Youth Studies, 16(3), 304-317. DOI: 10.1080/13676261.2012.718435

[14] Seif, R. (2017). The media representation of fictional gay and lesbian characters on television. June 11, 2019 http://www.divaportal.org/smash/get/diva2:1111368/FULLTEXT01.p df

[15] Laporte, R. (1992). The butch-femme question. In J. Nestle (Ed.), The persistent desire: A butch-femme reader, 208-219. Boston, MA: Alyson Publications.

[16] Walker, J., Golub, S., Bimbi, D. \& Parsons, J. (2012) Butch bottomfemme top? an exploration of lesbian stereotypes. Journal of Lesbian Studies 16(1), 90-107. DOI: 10.1080/10894160.2011.557646 
[17] Gomez, J. (1998). Femme erotic independence. In S. Munt (Ed.). Butch-femme: Inside lesbian gender, 101-108. London, England: Cassell

[18] Levitt, H., \& Hiestand, K. (2004). A quest for authenticity: a contemporary butch gender. Sex Roles 50(9/10), 605-621.

[19] Constant, S. J. (2018). Heterotopias and utopias in Black Mirror: Michael Foucault on "San Junipero". In A. M. Cirucci, \& B. Vacker
(Eds.). Black Mirror and Critical Media Theory, 213-222. Maryland: Lexington Book.

[20] Moura, G. (2014). 'Mise-en-scene: elements of cinema. July 28, 2019 http://www.elementsofcinema.com/?s=mise+ 